University of Nebraska - Lincoln

DigitalCommons@University of Nebraska - Lincoln

USDA National Wildlife Research Center - Staff Publications
U.S. Department of Agriculture: Animal and Plant Health Inspection Service

2018

\title{
Identifying individual cougars (Puma concolor) in remote camera images - implications for population estimates
}

\author{
Peter D. Alexander \\ Utah State University, pete@beringiasouth.org \\ Eric M. Gese \\ USDA National Wildlife Research Center
}

Follow this and additional works at: https://digitalcommons.unl.edu/icwdm_usdanwrc

Part of the Life Sciences Commons

\begin{abstract}
Alexander, Peter D. and Gese, Eric M., "Identifying individual cougars (Puma concolor) in remote camera images - implications for population estimates" (2018). USDA National Wildlife Research Center - Staff Publications. 2158.
\end{abstract}

https://digitalcommons.unl.edu/icwdm_usdanwrc/2158

This Article is brought to you for free and open access by the U.S. Department of Agriculture: Animal and Plant Health Inspection Service at DigitalCommons@University of Nebraska - Lincoln. It has been accepted for inclusion in USDA National Wildlife Research Center - Staff Publications by an authorized administrator of DigitalCommons@University of Nebraska - Lincoln. 


\title{
Identifying individual cougars (Puma concolor) in remote camera images - implications for population estimates
}

\author{
Peter D. Alexander ${ }^{\mathrm{A}, \mathrm{C}}$ and Eric M. Gese ${ }^{\mathrm{B}}$ \\ A Department of Wildland Resources, Utah State University, Craighead Beringia South, Kelly, WY 83011, USA. \\ BUnited States Department of Agriculture, Wildlife Services, National Wildlife Research Center, \\ Department of Wildland Resources, Utah State University, Logan, UT 84322-5230, USA. \\ ${ }^{\mathrm{C}}$ Corresponding author. Email: pete@beringiasouth.org
}

\begin{abstract}
Context. Several studies have estimated cougar (Puma concolor) abundance using remote camera trapping in conjunction with capture-mark-recapture (CMR) type analyses. However, this methodology (photo-CMR) requires that photo-captured individuals are individually recognisable (photo identification). Photo identification is generally achieved using naturally occurring marks (e.g. stripes or spots) that are unique to each individual. Cougars, however, are uniformly pelaged, and photo identification must be based on subtler attributes such as scars, ear nicks or body morphology. There is some debate as to whether these types of features are sufficient for photo-CMR, but there is little research directly evaluating its feasibility with cougars.

Aim. We aimed to examine researchers' ability to reliably identify individual cougars in photographs taken from a camera-trapping survey, in order to evaluate the appropriateness of photo-CMR for estimating cougar abundance or CMR-derived parameters.

Methods. We collected cougar photo detections using a grid of 55 remote camera traps in north-west Wyoming, USA. The photo detections were distributed to professional biologists working in cougar research, who independently attempted to identify individuals in a pairwise matching process. We assessed the level to which their results agreed, using simple percentage agreement and Fleiss's kappa. We also generated and compared spatially explicit capture-recapture (SECR) density estimates using their resultant detection histories.

Key results. There were no cases where participants were in full agreement on a cougar's ID. Agreement in photo identification among participants was low $(n=7$; simple agreement $=46.7 \%$; Fleiss's kappa $=0.183)$. The resultant $\mathrm{SECR}$ density estimates ranged from 0.7 to 13.5 cougars per $100 \mathrm{~km}^{2}(\mathrm{n}=4$; s.d. $=6.11)$.

Conclusion. We were unable to produce reliable estimates of cougar density using photo-CMR, due to our inability to accurately photo-tag detected individuals. Abundance estimators that do not require complete photo-tagging (i.e. mark-resight) were also infeasible, given the lack of agreement on any single cougar's ID.

Implications. This research suggested that there are substantial problems with the application of photo-CMR to estimate the size of cougar populations. Although improvements in camera technology or field methods may resolve these issues, researchers attempting to use this method on cougars should be cautious.
\end{abstract}

Received 24 March 2017, accepted 30 March 2018, published online 20 June 2018

\section{Introduction}

The use of remote cameras to monitor animal populations has increased dramatically in recent years due to improvements in camera technology and cost-effectiveness. With this rapid adoption, however, some important assumptions of camera trapping methodology and analysis may not always be fully considered (Burton et al. 2015). One common application uses camera trapping in conjunction with capture-mark-recapture (CMR) analyses for estimating animal abundance or other parameters. This can be a valuable tool when conventional sighting or tagging methods are expensive or infeasible. Cougars (Puma concolor) are a cryptic, low density and difficult-tocapture species, and as such are an attractive candidate for this method. However, a fundamental assumption of CMR is that individuals, once captured, can be reliably identified in subsequent recaptures (Otis et al. 1978; Seber 1982). In a conventional live-trapping scenario, this is achieved by affixing a unique ID tag to the captured individual. Under the non-invasive framework of camera trapping (photo-CMR), no artificial tags are used; instead, individuals are identified by some visible trait that is both individually distinct and discernible in a photograph. Conspicuously striped or spotted animals such as tigers (Panthera tigris) or jaguars (Panthera onca) are thus ideal, given their individually unique markings that serve, essentially, as innate ID tags (Karanth 1995; Silver et al. 2004). 
Cougars, however, are a uniformly pelaged species that lack such markings, and there has been some debate on their suitability for photo-CMR. Nevertheless, several studies have estimated cougar abundance using photo-CMR, under the assumption that individuals could be identified by traits such as kinked tails, ear nicks, scars or body shape (e.g. Kelly et al. 2008; Paviolo et al. 2009; Negrões et al. 2010; Soria-Díaz et al. 2010; Ávila-Nájera María et al. 2015; Quiroga et al.2016). Kelly et al. (2008) examined the feasibility of photo-tagging cougars where the authors quantified the extent to which independent investigators agreed with one another when assigning ID to cougars in remote camera images. They found $72.9 \%$ average agreement between three independent investigator teams examining 35-48 cougar detections from three study areas, and determined that, with certain stipulations, cougar abundance could be estimated using photo-CMR. Foster and Harmsen (2012), however, provided two considerations that shed some doubt on the accuracy of photo-tagging cougars: (1) traits such as kinked tails and notched ears, while distinctive, may not be individually unique, and with larger sample sizes the likelihood of multiple cougars with the same trait would likely increase; and (2) the apparent size and morphology of individuals in photographs can be highly impacted by factors such as ambient lighting, flash type, angle and/or distance to camera and recent feeding history. Both analytical methods and field techniques have been proposed to deal with this potential issue. Rich et al. (2014) proposed mark-resight analyses (Arnason et al. 1991), which required that only a subset of detected individuals are assigned an ID. This method is potentially ideal, assuming at least some subset of cougars in a population has distinguishing features that allow for reliable photo identification. McBride and Sensor (2015) suggested the use of scent lures to encourage an individual to 'linger' at a camera, in order to increase the number of photos per capture event, and thus help in photo identification.

Our review of the literature suggests potentially serious issues with photo-identifying individual cougars in remote camera images. Despite this, studies have continued to report photoCMR estimates of cougar abundance or density, and there has been little research that directly addresses the method's potential problems or evaluates its proposed solutions. Our goals were to (1) evaluate researcher ability to individually identify cougars in remote camera images following the Kelly et al. (2008) approach, (2) examine the effects that differing detection histories may have on density estimates and (3) examine the practicality of some proposed methods such as mark-resight (Rich et al. 2014) and increasing photos per detection (McBride and Sensor 2015).

\section{Materials and methods}

\section{Study area}

Camera trapping was performed in the Jackson Hole basin in north-west Wyoming, USA (Fig. 1). The majority of this area was administered by the USA Forest Service (BridgerTeton National Forest), or the National Park Service (Grand Teton National Park). A small percentage $(<2 \%)$ was privately owned ranches or residential areas. Elevations ranged from $\sim 2025 \mathrm{~m}$ to $\sim 3420 \mathrm{~m}$. Vegetation included cottonwood (Populus angustifolia) riparian zones interspersed by sagebrush (Artemisia spp.) uplands at lower elevations. At higher elevations, aspen (Populus tremuloides), Douglas-fir (Pseudotsuga menziesii), Engelmann spruce (Picea engelmannii) and other conifers (Pinus spp., Abies spp.) were the predominant forest cover (Marston and Anderson 1991; Knight 1996).

Besides cougars, the study area included grizzly bears (Ursus arctos), black bears (Ursus americanus) and grey wolves (Canis lupus). Mesocarnivores included coyotes (Canis latrans) and red foxes (Vulpes vulpes). Primary prey species included mule deer (Odocoileus hemionus), elk (Cervus elaphus), white-tailed deer (Odocoileus virginianus), moose (Alces alces), bighorn sheep (Ovis canadensis) and various small to medium-sized mammal and avian species.

\section{Field methods}

This research was performed in the context of a larger, multiyear study on non-invasive survey methods for cougars (Alexander 2016), and followed the code of practice outlined by the Jackson Institutional Animal Care and Use Committee (Protocol 027-10EGDBS-060210). Cougar images were generated from 55 remote camera stations, active between mid-June and mid-September of 2013. Camera stations were spaced such that the typical home-range size of a female cougar would encompass four camera sites (Rovero et al. 2013). The fine-scale locations of camera stations were selected based on topographic or vegetative features typical of cougar habitat or travel routes; these sites were generally characterised by ridgelines, drainage bottoms or edge habitat where cougars were either known (via GPS collar or natural sign) or suspected to travel. The majority of the sites $(n=43)$ used two cameras, fixed to trees, $\sim 50$ to $80 \mathrm{~cm}$ off the ground and $10-15 \mathrm{~m}$ apart, with both cameras aimed in a manner to capture two sides of an animal as it passed through the site. Between the cameras, we suspended an open container of non-reward lure ( $\sim 3 \mathrm{~L}$ of blood waste from cattle abattoirs), $\geq 3.5 \mathrm{~m}$ off the ground. We added sodium citrate to prevent coagulation and thus retain odour (Haroldson and Anderson 1996). We also suspended a repurposed compact disc to act as a visual curiosity attractor. Below the lure, we planted an $80-\mathrm{cm}$ high stake, marked at $10-\mathrm{cm}$ increments to help estimate animal height and aid in individual identification (Fig. 2). The two cameras were different models: a non-commercial white-flash model designed by Panthera (Panthera Inc., New York); and a commercially available infrared-flash model Reconyx PC800 (Reconyx, Inc., Holmen, WI). All camera models used a passive infrared sensor for motion-triggered activation. The Panthera model's white flash produced high quality colour night-time images, but was relatively slow to recharge $(\sim 15 \mathrm{~s})$ and generally produced fewer night-time images per detection event than the Reconyx cameras. Additional camera sites $(n=12)$ were set up using conventional camera-trapping methods, with single Panthera cameras placed along high-use trails (e.g. Karanth 1995; Negrões et al. 2010). We placed $\leq 1 \mathrm{~mL}$ of scent 'Calvin Klein Obsession for Men' (Calvin Klein Inc., New York) and synthetic civet musk or catnip oil (Grawe's Lures, Wahpeton, ND) - on the ground, in front of the cameras. We performed site visits every 2 weeks to monitor the stations 


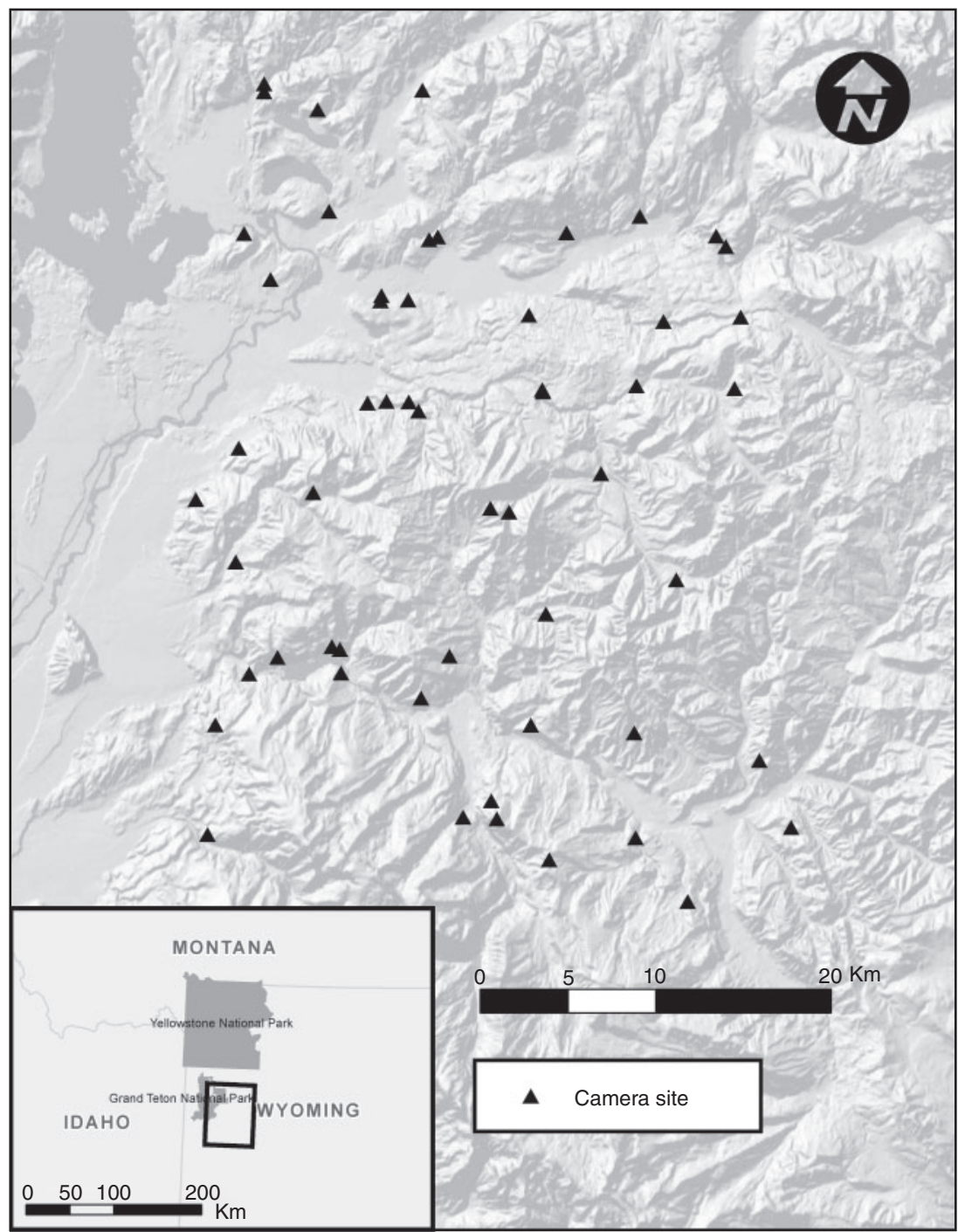

Fig. 1. Locations of 55 remote camera stations used to survey cougars in north-west Wyoming, USA. The minimum convex polygon encompassing the stations covered $1287 \mathrm{~km}^{2}$.

and download photos. We replenished the blood lure every 4 weeks, or as needed.

\section{Identification process and survey}

As with Kelly et al. (2008), we were unable to know with certainty the actual IDs of photo-trapped individuals, and our assessment was based on the level of agreement between independent investigators assigning ID. An important limitation to this method is that strong agreement between investigators would not necessarily indicate accuracy of the assigned IDs. High disagreement, however, would be a compelling indicator that photo-identifying cougars is an unreliable tagging method, which likely violates the assumptions of CMR and produces poor estimates of abundance.

Photos were catalogued using Microsoft Access (Microsoft Corporation, Redmond, WA). We organised photos into detection events, with each event having at least one photo of a single individual. Events at the same site were considered separate if greater than $1 \mathrm{~h}$ elapsed between photos (Kelly et al. 2008). If multiple cougars were simultaneously detected (e.g. a family group or courting pair), the photos were duplicated such that there was one event per individual cougar. We designed an electronic form to accompany the database, allowing a user to sort through photo-capture events and assign ID. The form displayed events in pairs, with one event shown on each side of the display. The form allowed users to scan through the events, as well as their constituent images, on each side of the screen independently (Fig. 2). This allowed users to perform pairwise comparisons between all events, and score each pairing as either being from the same individual or two different individuals. The user could monitor the resultant detection history, allowing them to verify and fix any inconsistencies (i.e. contradictory matches). Also included were spatial and temporal data for each event, with the spatial and temporal separation between the paired events automatically 


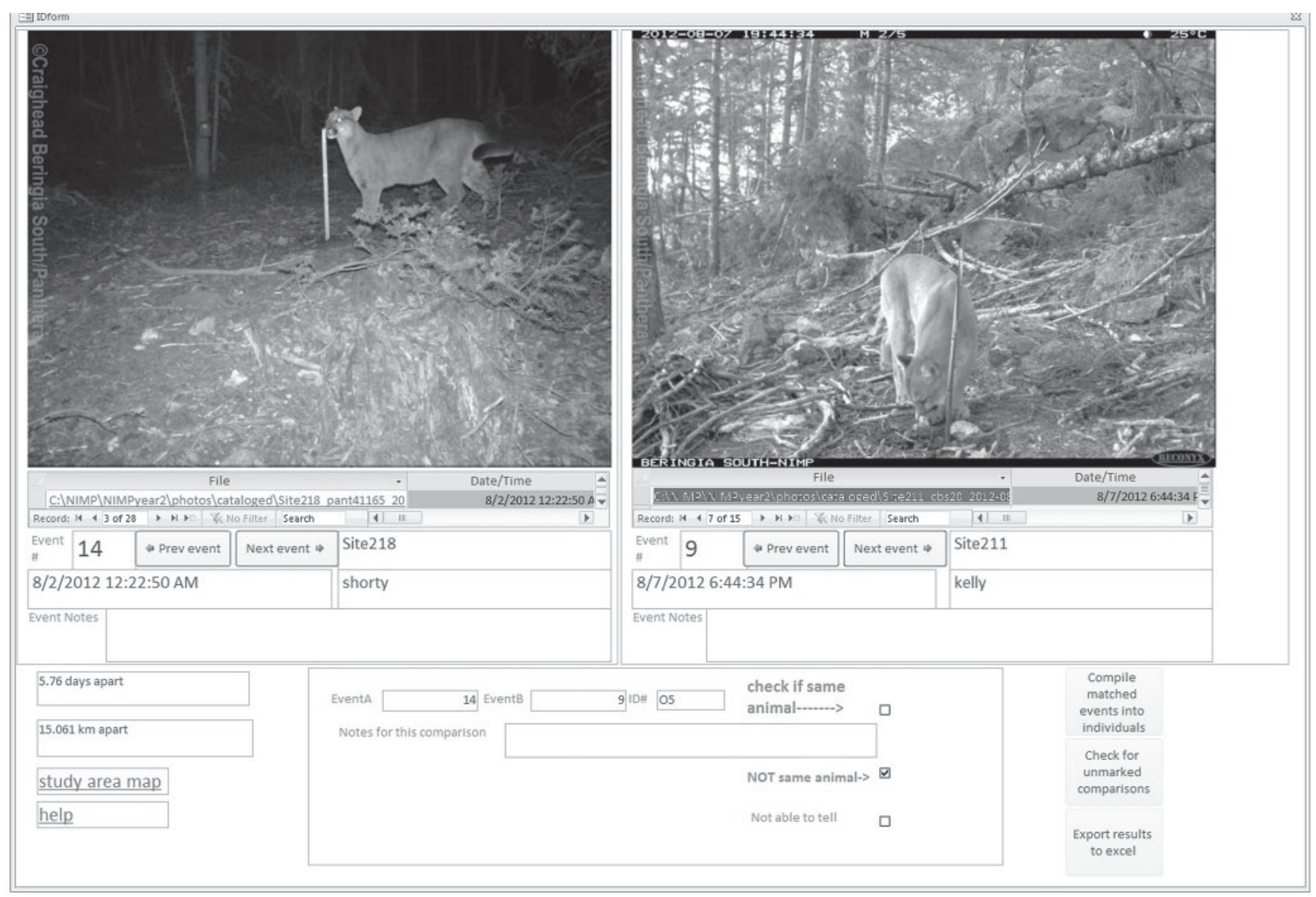

Fig. 2. A screen capture from the identification process where two cougar detection events are displayed on each side of the screen, north-west Wyoming, USA. Users could scroll through and examine all photos within a detection event, independently on each side of the screen. Users designated the two detection events either as being the same, or as distinct, individuals.

calculated and displayed (e.g. 'events A and B were $10.5 \mathrm{~km}$ and $51.3 \mathrm{~h}$ apart'). We considered this information 'fair game', because we believed these data would logically be included in a real-world scenario, and should therefore be included in the analysis. We evaluated all possible pairwise combinations of events, resulting in $\left(\begin{array}{l}n \\ 2\end{array}\right)$ pairings, where $\mathrm{n}$ is the number of events. We distributed the Access database to independent participants. We considered only wildlife researchers who had considerable experience with cougars for participation. A segment of the participants included biologists who were involved in the cougar research in the study area and were familiar with some of the detected cougars.

Due to the combinatoric nature of the evaluation process, the number of pairings (and the time required for evaluation) increased exponentially with the number of detection events. Given that the full set of detections produced 300 pairings (see Results), we thus completed two types of surveys: (1) a full-set survey, in which participants analysed all 300 pairings of all cougar detection events; and (2) a subset survey, in which participants analysed a subset of detection events, thereby restricting the number of pairing evaluations and requiring less time. In order to create the shorter subset survey, we discarded detections with radio-collared cougars and detections with poorer quality photos. We chose these events for removal because this had the added benefit of reducing the potential for participants to (1) identify an individual based on their radio-collar, or (2) misidentify an individual due to a low quality image as opposed the appearance of the animal itself.

\section{Density estimates and agreement analysis}

For each of the full-set survey results, we calculated the density estimate using spatially explicit capture-recapture (SECR) with the R package secr (Efford 2015). SECR works by combining an observation model based on the spatially explicit capture history, and a state model describing the distribution of potential home range centres across the landscape, represented by a 'habitat mask' of points in secr. For the habitat mask, we used a layer of homogenous points, spaced at $1 \mathrm{~km}$ and delineated by a $6-\mathrm{km}$ buffer around the camera station minimum convex polygon. The capture history was divided into eight 10-day occasions. Only the null model was run.

For the subset survey, we calculated participant agreement using the R package irr (Gamer et al. 2014). We calculated two types of agreement: (1) simple percentage agreement, similar to the metric used in Kelly et al. (2008); and (2) Fleiss's kappa (Fleiss 1971), a more statistically rigorous measure of agreement (Gwet 2010). A kappa statistic ranges 
from 0 to 1 , with 1 indicating perfect agreement, and 0 indicating a level of agreement consistent with completely random scorings by participants. We also examined the relationship between the strength of the blood scent at camera sites and the capture event length (McBride and Sensor 2015) and regressed the time length of cougar detection events against the 'freshness' of the non-reward blood lure. We defined the visitation length as the time between the first and last photo taken, in seconds. Freshness was determined by the latency in days since the non-reward blood lure was placed. Finally, to examine the relationship between ID success and the number of photos per event, we ran a generalised linear model with a Poisson distribution, using the count of participants in agreement for each event pairing as the response variable and the total number of photos in the detection event pairing as the predictor variable.

\section{Results}

The minimum convex polygon encompassing all camera stations was $1287 \mathrm{~km}^{2}$. The camera array was active for a total of 3993 sampling days. The mean trap spacing for the 55 camera stations

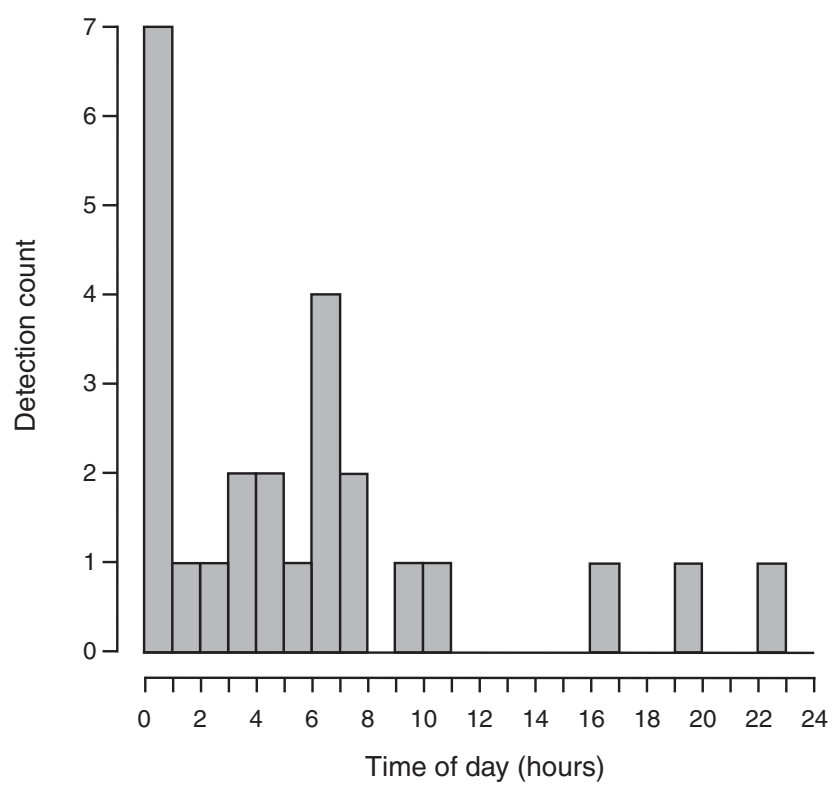

Fig. 3. Detection activity of cougars by time of day, based on remote camera data, north-west Wyoming, USA. was $2759 \mathrm{~m}$. We collected a total of 308 photos of cougars, which comprised 25 separate cougar detection events. Detections were generally at night or during crepuscular hours (Fig. 3), with the majority of those photos being black and white infrared images. The average number of photos per detection event was 12.32 ( \pm 9.78 s.d., minimum $=1$, maximum $=32$ photos $)$. The average event time length of the blood-lure detections was $57.44 \mathrm{~s}( \pm 60.20$ s.d., minimum $=1$, maximum $=214 \mathrm{~s})$.

Seven participants completed the subset survey, with four of those participants also finishing the full-set survey. For the full-set survey of all 25 events (300 combinations of event pairs), results were highly varied: the number of individuals identified ranged by a $100 \%$ difference (minimum $=8$, maximum $=24$ ), and the SECR density estimates ranged by a $180 \%$ difference (minimum $=0.70$ cougars per $100 \mathrm{~km}^{2}$, maximum 13.47 cougars per $100 \mathrm{~km}^{2}$; Table 1 ).

For the subset survey, we removed events with radiocollared cougars $(n=5)$ or poor quality photos $(n=5)$. This resulted in a subset of 15 events, or 105 combinations of event pairs. The number of individuals identified by those seven participants ranged from 4 to 13 (106\% difference). We calculated a $46.7 \%$ simple agreement between participants. Fleiss's kappa was $0.183(P<0.001)$. Although interpretation of kappa values is somewhat subjective (Gwet 2010), this value would be categorised as 'slight' (Landis and Koch 1977) or 'poor' agreement (Fleiss et al. 1981). There were no cases when all seven participants ascribed a pairing to the same individual. Out of the 105 event pairings, there were only six with $>50 \%$ of participants scoring them as 'same'. The mean spatial distance between events with $>50 \%$ of participants differentiating individuals was $18.1 \mathrm{~km}( \pm 8.4$ s.d., $n=99)$, and the mean distance between pairings with $>50 \%$ of participants ascribing 'same' status was $1.3 \mathrm{~km}( \pm 3.1$ s.d., $n=6)$. Of the six pairings with $>50 \%$ 'same' agreement, four were from event pairs occurring at the same camera station.

Additionally, we found that agreement increased as the number of investigators decreased: we reran our calculations for simple percentage agreement using all possible combinations and subsets of the participant pool. The mean percentage agreement for any subset of three investigators increased to $71.4 \%$ ( \pm 13.5 s.d.) and ranged from $54.3 \%$ to $91.4 \%$ (Fig. 4 ).

We found evidence that scent increased the length of a cougar detection event (thereby increasing the number of photos per event). There was a negative correlation between length of a cougar's visit (in seconds) and the latency since the non-reward blood lure was placed $(\beta=-2.134$, s.e. $=1.036$,

Table 1. Spatially explicit capture-recapture (SECR) results, based on independent observers building photo-detection histories from the same set of camera trap photos from North-west Wyoming, USA

The second column is the number of unique individuals that were identified by the observers. The discrepant detection histories resulted in varying density results, estimates of detection probability $\left(\mathrm{g}_{0}\right)$ and the detection function scaling parameter $\sigma$ (reported in metres). Estimates are reported with $95 \%$ confidence intervals ( $\mathrm{LCL}=$ lower, $\mathrm{UCL}=$ upper). Inf, infinity

\begin{tabular}{|c|c|c|c|c|c|c|c|c|c|c|}
\hline & $\mathrm{N}$ animals & Density (per $100 \mathrm{~km}^{2}$ ) & $95 \% \mathrm{LCL}$ & $95 \% \mathrm{UCL}$ & $\mathrm{g}_{0}$ & $95 \% \mathrm{LCL}$ & $95 \% \mathrm{UCL}$ & $\sigma$ & $95 \% \mathrm{LCL}$ & $95 \%$ UCL \\
\hline Obs 1 & 12 & 0.70 & 0.39 & 1.34 & 0.04 & 0.02 & 0.08 & 5540 & 3910 & 7852 \\
\hline Obs 2 & 8 & 0.39 & 0.19 & 0.78 & 0.04 & 0.02 & 0.07 & 8989 & 6525 & 12385 \\
\hline Obs 3 & 24 & 13.47 & 1.99 & 90.95 & $<0.01$ & $<0.01$ & $<0.01$ & $8.68 \times 10^{6}$ & 0 & Inf \\
\hline Obs 4 & 22 & 4.04 & 1.44 & 11.36 & $<0.01$ & $<0.01$ & 0.02 & 7182 & 3990 & 12929 \\
\hline
\end{tabular}




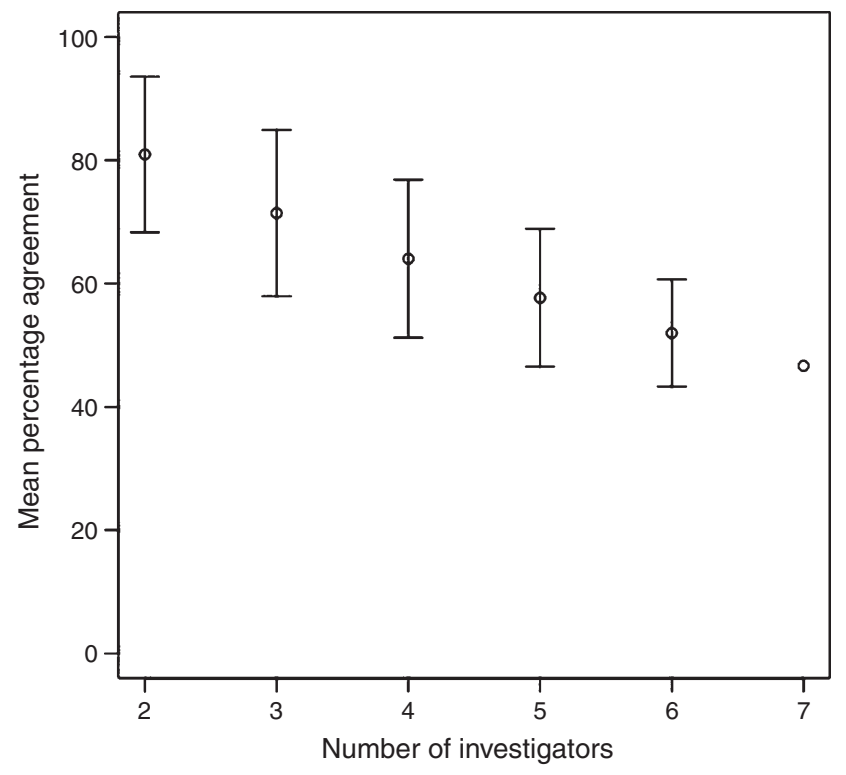

Fig. 4. Simple percentage agreement for any subset of the seven participating investigators independently assigning ID to photo-detected cougars in north-west Wyoming, USA. Bars represent standard deviation for all possibly subsets (there is no variance when all seven participants were included).

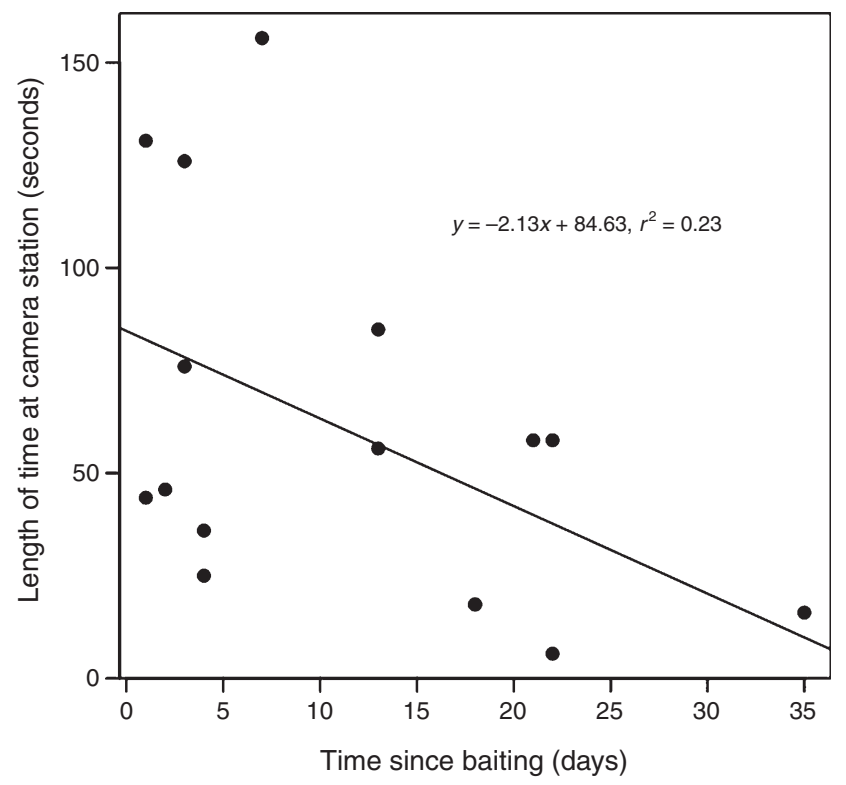

Fig. 5. Length of time a cougar spends at a camera station in relation to the age of the non-reward blood lure, north-west Wyoming, USA. Likely, a stronger smelling lure provoked a cougar to linger, thus increasing the number of photos taken.

$P=0.058$; Fig. 5). However, we found no significant correlation between the number of photos per event and simple percentage agreement $(\beta=-0.009$, s.e. $=0.008, P=0.24)$. We also used a spatiotemporal measure of the minimum speed required for an individual cougar to be present at both events in a matching. We used the natural log-transformation to normalise the value and found a significant negative correlation $(\beta=-0.21$, s.e. $=0.03, P<0.001)$ between higher minimum speed and count of 'same' designations, suggesting that distance and time between detections were important in participants' assessments.

\section{Discussion}

Agreement among participants assigning ID was low, and there were no cases of complete agreement on any single ID. The $46.7 \%$ simple agreement was completely driven by agreement on differentiated cougars (i.e. in $46.7 \%$ of the event pairings, all seven participants agreed that the two events detected different cougars). These results highlight the difficulty of individually identifying cougars in camera trap images, and suggest that photo-identification based detection histories may be overly prone to misidentification errors. These results correspond with the high photoidentification error rates found for other uniformly pelaged species such as lowland tapirs (Tapirus terrestris; OliveiraSantos et al. 2010) and red foxes (Vulpes vulpes; Güthlin et al. 2014). Other studies have shown that such misidentification errors, and their resultant capture histories, can create large variances in abundance estimates (Creel et al. 2003; Yoshizaki et al. 2009). This concern is upheld by our four full-survey SECR densities, which varied widely (Table 1). SECR can be prone to other sources of bias, notably trap array size and spacing (Sollmann et al. 2012; Sun et al. 2014). However, these factors should not have biased our results, because our trap array was larger than individual cougar movements (Sollmann et al. 2012). Although the full-survey SECR parameter estimates were biased by the misidentification errors, we note that three of the four estimates of $\sigma$ were greater than half the trap spacing, and consistent with trap spacing recommendations by Sollmann et al. (2012) and Sun et al. (2014).

The only other study we are aware of that attempted to measure the level of agreement between independent observers identifying cougars in camera trapping photos was Kelly et al. (2008). Importantly, that study did not use our technique of measuring agreement over all possible pairwise matches, so their measure of agreement does not necessarily compare to ours. Nevertheless, our interpretations differed markedly in terms of our assessments of photo-CMR and its appropriateness for cougars. One possible reason is that Kelly et al. (2008) identified cougars in tropical regions, where botfly (family Oestridae) scars may have aided in correct identification (e.g. Negrões et al. 2010; Harmsen et al. 2010). Depending on the longevity of botfly scars, pervasiveness of botfly parasites in the cougar population and length of survey, these marks could potentially be as distinctive as conspicuously pelaged species (e.g. tigers, jaguars). If this is indeed the case, then our findings may not necessarily call into question the cougar abundance estimates from photo-CMR studies performed in tropical regions. Alternatively, the fewer number of independent investigators used by Kelly et al. (2008) may have increased the probability of chance agreement. This is supported by our finding that subsampling combinations of participants resulted in increased mean agreement level. 
Given that participants had a binary choice (i.e. 'same' or 'different') for the event matchings, reducing the number of participants likely increased the probability of random agreement.

Two general strategies have been proposed in the literature to deal with these high misidentification rates: (1) techniques that allow for greater ID success; and (2) alternative analysis methods to reduce model bias from misidentification. In terms of the first strategy, we explicitly examined the use of scent lures to improve ID success (McBride and Sensor 2015). We did find evidence that scent can encourage a cougar to linger at a camera site, thereby increasing the number of photos per detection. Surprisingly, however, increasing the number of photos per event matching did not correlate with any improvement in agreement level. We also incorporated the use of measurement posts at camera sites to aid in size estimation; however, the level of effectiveness was unclear due to the lack of agreement between participants. While outside the scope of our study, we note that improvements in camera trap technology, methodology or image analyses could improve ID success. Camera technology that increases photo quality and image resolution could increase observers' abilities to identify distinct features. Computer-aided identification methods (i.e. biometrics or pattern recognition; see Kühl and Burghardt 2013) could also improve identification success. Generally, these computer aided processes still require conspicuous markings or patterns (Kühl and Burghardt 2013), and the photo detections from our research may still not be suitable. However, novel camera trapping methods that standardise the angle or position of the animal, or consistently capture some finer-scale feature may allow for these types of analyses. Examples include camera trapping methods that target ventral markings of wolverines (Gulo gulo; Magoun et al. 2011) or American martens (Martes americana; Sirén et al. 2016). A feature more applicable to cougars may be whisker spot patterns, which have been used to individually identify African lions (Panthera leo; Pennycuick and Rudnai 1970) and polar bears (Ursus martimus; Anderson et al. 2007). In the latter study, photographs of bears were taken with handheld cameras with high-quality telephoto lenses; it is conceivable that novel camera trapping technologies or methodologies could duplicate that approach with cougars.

The second strategy uses alternative modelling, such as mark-resight models that do not require all detected animals to be tagged (Rich et al. 2014). As implemented by Rich et al. (2014), only those detections for which independent observers fully agreed on ID would be categorised as marked. Critically, we had no cases of complete agreement on any single assigned ID, thus precluding mark-resight analysis. We note that there also exist models that attempt to account for misidentification bias (Yoshizaki et al. 2009). However, these were likely inappropriate for our data, due to the possibility of both false mismatches and false matches, as well as the low detection probabilities (Table 1).

Cougars have been proposed as a focal species (Lambeck 1997) in conservation efforts, due to their roles as flagship and umbrella species (Beier 2009), as well as their potential keystone functions as multi-trophic regulators (Ripple and Beschta 2006; Beier 2009). Yet, cougar populations have undergone large range contractions over the past century due to habitat loss, habitat fragmentation and direct human persecution (Ripple et al. 2014). Accurate population monitoring tools are thus needed, for both the implementation and evaluation of management and conservation efforts. Although photo-CMR is, ostensibly, an appealing solution to the difficulties in monitoring cougar populations, our results highlight important concerns with the method. Likely, these issues extend to other uniformly pelaged species, and the implications of our work do not apply strictly to cougar research. Researchers should carefully consider their ability to accurately identify their study animals when using remote camera traps. In cases when photo identification may not be reliable, alternative techniques such as non-invasive genetic sampling may be a more practical method.

\section{Conflicts of interest}

The authors declare no conflicts of interest.

\section{Acknowledgements}

Funding and logistical support provided by Panthera, Craighead Beringia South, the Summerlee Foundation, the Paisley Foundation and the USDANational Wildlife Research Center. We thank the Wyoming Game and Fish Department, Grand Teton National Park, Bridger-Teton National Forest and the National Elk Refuge for their support and collaboration. We also thank the Gros Ventre and Buffalo Valley landowners for their cooperation. Thanks to M. Cuthill, G. Davidson, M. Elbroch, P. Lendrum, K. Murphy, J. Newby, C. O'Malley and D. Thompson for participating in the photo matching surveys. We thank D. Thompson and D. MacNulty for their thoughtful reviews. Additional thanks to D. Craighead, H. Quigley, M. Elbroch and the Teton Cougar Project for their collaboration with captures, fieldwork and use of trucks and equipment, and to B. Smith and the Smith family for their expertise and endless energy during captures. We thank R. Crandle, J. Newby, M. Cuthill, P. Lendrum, K. Murphy, C. O'Malley, P. Abdu, S. Beckett, C. Bowden, M. Boyce, A., Z. Dautrich, S. Dwinnel, S. Ellis, S. Farnsworth, J. Fitzpatrick, J. Kay, A. Kulser, A. Loosen and A. Tyson for logistical and field assistance.

\section{References}

Alexander, P. D. (2016). Comparing conventional and noninvasive monitoring techniques for assessing cougar population size in the southern greater Yellowstone ecosystem. Ph.D. Thesis, Utah State University, Logan.

Anderson, C. J. R., Roth, J. D., and Waterman, J. M. (2007). Can whisker spot patterns be used to identify individual polar bears? Journal of Zoology 273, 333-339. doi:10.1111/j.1469-7998.2007.00340.x

Arnason, A. N., Schwarz, C. J., and Gerrard, J. M. (1991). Estimating closed population size and number of marked animals from sighting data. The Journal of Wildlife Management 55, 716-730. doi:10.2307/ 3809524

Ávila-Nájera María, D., Chávez, C., Lazcano-Barrero, M. A., Pérez-Elizalde, S., and Alcántara-Carbajal, J. L. (2015). Population estimates and conservation of felids (Carnivora: Felidae) in Northern Quintana Roo, Mexico. International Journal of Tropical Biology and Conservation 63, 799-813.

Beier, P. (2009). A focal species for conservation planning. In 'Cougar: Ecology and Conservation'. (Eds M. Hornocker and S. Negri.) pp. 177-189. (University Of Chicago Press: Chicago, IL.)

Burton, A. C., Neilson, E., Moreira, D., Ladle, A., Steenweg, R., Fisher, J. T., Bayne, E., and Boutin, S. (2015). Wildlife camera trapping: a review 
and recommendations for linking surveys to ecological processes. Journal of Applied Ecology 52, 675-685. doi:10.1111/1365-2664.12432 Creel, S., Spong, G., Sands, J. L., Rotella, J., Zeigle, J., Joe, L., Murphy, K. M., and Smith, D. (2003). Population size estimation in Yellowstone wolves with error-prone noninvasive microsatellite genotypes. Molecular Ecology 12, 2003-2009. doi:10.1046/j.1365-294X.2003.01868.x

Efford, M. (2015). Package 'secr'. R package version 2.9.4. Available at http://cran.r-project.org/package=secr [verified 25 March 2015]

Fleiss, J. L. (1971). Measuring nominal scale agreement among many raters. Psychological Bulletin 76, 378-382. doi:10.1037/h0031619

Fleiss, L., Levin, B., and Paik, M. C. (1981). The measurement of interrater agreement. In 'Statistical Methods for Rates and Proportions'. (Ed. K. McPherson.) pp. 598-626. (John Wiley \& Sons, Inc.: Hoboken, NJ.)

Foster, R. J., and Harmsen, B. J. (2012). A critique of density estimation from camera-trap data. The Journal of Wildife Management 76, 224-236. doi:10.1002/jwmg. 275

Gamer, M., Lemon, J., Fellows, I., and Singh, P. (2014). Package 'irr'. Available at https:// cran.r-project.org/package=irr [verified 16 May 2018]

Güthlin, D., Storch, I., and Küchenhoff, H. (2014). Is it possible to individually identify red foxes from photographs? Wildlife Society Bulletin 38, 205-210. doi:10.1002/wsb.377

Gwet, K. L. (2010). 'Handbook of Inter-rater Reliability: the Definitive Guide to Measuring the Extent of Agreement Among Raters.' (Advanced Analytics, LLC: Gaithersburg, MD.)

Harmsen, B. J., Foster, R. J., Gutierrez, S. M., Marin, S. Y., and Patrick, C. (2010). Scrape-marking behavior of jaguars (Panthera onca) and pumas (Puma concolor). Journal of Mammalogy 91, 1225-1234. doi:10.1644/09-MAMM-A-416.1

Haroldson, M., and Anderson, C. (1996). Effectiveness of attractants to lure grizzly bears into hair collection sites for future DNA fingerprinting. Annual report of the Interagency Grizzly Bear Study Team, 1996. U.S. Geological Survey, Bozeman, MT, USA.

Karanth, K. U. (1995). Estimating tiger Panthera tigris populations from camera-trap data using capture-recapture models. Biological Conservation 71, 333-338. doi:10.1016/0006-3207(94)00057-W

Kelly, M. J., Noss, A. J., Di Bitetti, M. S., Maffei, L., Arispe, R. L., Paviolo, A., De Angelo, C. D., and Di Blanco, Y. E. (2008). Estimating puma densities from camera trapping across three study sites: Bolivia, Argentina, and Belize. Journal of Mammalogy 89, 408-418. doi:10.1644/ 06-MAMM-A-424R.1

Knight, D. H. (1996). 'Mountains and Plains: the Ecology of Wyoming Landscapes.' (Yale University Press: New Haven, CT.)

Kühl, H. S., and Burghardt, T. (2013). Animal biometrics: quantifying and detecting phenotypic appearance. Trends in Ecology \& Evolution 28, 432-441. doi:10.1016/j.tree.2013.02.013

Lambeck, R. (1997). Focal species: a multi-species umbrella for nature conservation. Conservation Biology 11, 849-856. doi:10.1046/j.15231739.1997.96319.x

Landis, J., and Koch, G. (1977). The measurement of observer agreement for categorical data. Biometrics 33, 159-174. doi:10.2307/2529310

Magoun, A. J., Long, C. D., Schwartz, M. K., Pilgrim, K. L., Lowell, R. E., and Valkenburg, P. (2011). Integrating motion-detection cameras and hair snags for wolverine identification. The Journal of Wildlife Management 75, 731-739. doi:10.1002/jwmg.107

Marston, R. a., and Anderson, J. E. (1991). Watersheds and vegetation of the Greater Yellowstone Ecosystem. Conservation Biology 5, 338-346. doi:10.1111/j.1523-1739.1991.tb00147.x

McBride, R., and Sensor, R. (2015). Efficacy of trail cameras to identify individual Florida panthers. Southeastern Naturalist (Steuben, ME) 14, 351-360. doi:10.1656/058.014.0215

Negrões, N., Sarmento, P., Cruz, J., Eira, C., Revilla, E., Fonseca, C., Sollmann, R., Tôrres, N. M., Furtado, M. M., Jácomo, A. T. A., and Silveira, L. (2010). Use of camera-trapping to estimate puma density and influencing factors in central Brazil. The Journal of Wildlife Management 74, 1195-1203. doi:10.1111/j.1937-2817.2010.tb01240.x Oliveira-Santos, L. G. R., Zucco, C. A., Antunes, P. C., and Crawshaw, P. G. (2010). Is it possible to individually identify mammals with no natural markings using camera-traps? A controlled case-study with lowland tapirs. Mammalian Biology 75, 375-378. doi:10.1016/j.mambio.2009. 08.005

Otis, D., Burnham, K., White, G., and Anderson, D. (1978). Statistical inference from capture data on closed animal populations. Wildlife Monographs 62, 3-135.

Paviolo, A., Di Blanco, Y. E., De Angelo, C. D., and Di Bitetti, M. S. (2009). Protection affects the abundance and activity patterns of pumas in the Atlantic Forest. Journal of Mammalogy 90, 926-934. doi:10.1644/ 08-MAMM-A-128.1

Pennycuick, C. J., and Rudnai, J. (1970). A method of identifying individual lion with an analysis of the reliability of identification. Journal of Zoology 160, 497-508. doi:10.1111/j.1469-7998.1970. tb03093.x

Quiroga, V. A., Noss, A. J., Paviolo, A., Boaglio, G. I., Di Bitetti, M. S., and Di, M. S. (2016). Puma density, habitat use and conflict with humans in the Argentine Chaco. Journal for Nature Conservation 31, 9-15. doi: 10.1016/j.jnc.2016.02.004

Rich, L. N., Kelly, M. J., Sollmann, R., Noss, A. J., Maffei, L., Arispe, R. L., Paviolo, A., De Angelo, C. D., Di Blanco, Y. E., and Di Bitetti, M. S. (2014). Comparing capture-recapture, mark-resight, and spatial mark-resight models for estimating puma densities via camera traps. Journal of Mammalogy 95, 382-391. doi:10.1644/13-MAMM-A-126

Ripple, W. J., and Beschta, R. L. (2006). Linking a cougar decline, trophic cascade, and catastrophic regime shift in Zion National Park. Biological Conservation 133, 397-408. doi:10.1016/j.biocon.2006.07.002

Ripple, W. J., Estes, J. A., Beschta, R. L., Wilmers, C. C., Ritchie, E. G., Hebblewhite, M., Berger, J., Elmhagen, B., Letnic, M., Nelson, M. P., Schmitz, O. J., Smith, D. W., Wallach, A. D., and Wirsing, A. J. (2014). Status and ecological effects of the world's largest carnivores. Science 343, doi:doi:

Rovero, F., Zimmermann, F., Berzi, D., and Meek, P. (2013). 'Which camera trap type and how many do I need?' A review of camera features and study designs for a range of wildlife research applications. Hystrix 24, 1-9.

Seber, G. A. F. (1982). 'The Estimation of Animal Abundance and Related Parameters.' 2nd edn. (Charles Griffith and Company, Ltd: London.) doi:10.1002/iroh.19740590517

Silver, S., Ostro, L., Marsh, L., and Maffei, L. (2004). The use of camera traps for estimating jaguar Panthera onca abundance and density using capture/recapture analysis. Oryx 38, 1-7. doi:10.1017/S0030605 304000286

Sirén, A., Pekins, P., Abdu, P., and Ducey, M. (2016). Identification and density estimation of American martens (Martes americana) using a novel camera-trap method. Diversity (Basel) 8, doi:10.3390/d8010003

Sollmann, R., Gardner, B., and Belant, J. L. (2012). How does spatial study design influence density estimates from spatial capture-recapture models? PLoS One 7, -e34575. doi:10.1371/journal.pone.0034575

Soria-Díaz, L., Monroy-Vilchis, O., Rodríguez-Soto, C., Zarco-González, M. M., and Urios, V. (2010). Variation of abundance and density of Puma concolor in zones of high and low concentration of camera traps in Central Mexico. Animal Biology (Leiden, Netherlands) 60, 361-371. doi:10.1163/157075610X523251

Sun, C. C., Fuller, A. K., and Royle, J. A. (2014). Trap configuration and spacing influences parameter estimates in spatial capture-recapture models. PLoS One 9, e88025. doi:10.1371/journal.pone.0088025

Yoshizaki, J., Pollock, K. H., Brownie, C., and Webster, R. A. (2009). Modeling misidentification errors in capture-recapture studies using photographic identification of evolving marks. Ecology 90, 3-9. doi: $10.1890 / 08-0304.1$ 